\title{
DESAFIOS DO FUNCIONAMENTO DE CONSELHOS DELIBERATIVOS EM RESERVAS EXTRATIVISTAS MARINHAS NA REGIÃO BRAGANTINA DO ESTADO DO PARÁ.
}

\author{
Ivanilde de Sousa do Espírito Santo ${ }^{1}$ \\ iD https://orcid.org/0000-0002-7618-0912 \\ Marc Piraux $^{2}$ \\ iD https://orcid.org/0000-0001-6549-2614
}

\begin{abstract}
RESUMO
O presente trabalho tem por objetivo analisar e comparar o funcionamento dos conselhos deliberativos das Reservas Extrativistas (RESEX) marinhas Caeté-Taperaçu e Araí-Peroba, a partir de alguns critérios da governança territorial. O estudo foi realizado nas RESEX Marinhas CaetéTaperaçu (município de Bragança) e na Araí-Peroba (município de Augusto Corrêa), criadas em 2005, na região nordeste do estado do Pará. O trabalho foi elaborado a partir de uma abordagem qualitativa. A coleta de dados se deu através de dados secundários, questionários e entrevistas semiestruturadas. Observou-se que, apesar das dificuldades, o conselho deliberativo da RESEX marinha Caeté-Taperaçu está funcionando, embora com uma gestão centralizada e ineficiente. Já o conselho deliberativo da RESEX marinha Araí-Peroba encontra-se inativo desde 2014. Os motivos foram: a falta de uma gestão descentralizada, o difícil acesso a RESEX, entendimento do significado de uma RESEX, forte assistencialismo e a política partidária. Conclui-se que, apesar da governança territorial ser uma inovação social para a gestão dos territórios de RESEX marinhas, nos conselhos deliberativos Caeté-Taperaçu e Araí-Peroba falta uma governança, visto que, identificou-se arranjos institucionais enfraquecidos e participações não efetivas das comunidades extrativistas no processo de decisão.
\end{abstract}

Palavras-Chave: Governança Territorial, Reserva Extrativista Marinha, Conselho Deliberativo.

\section{CHALLENGES IN THE FUNCTIONING OF DELIBERATIVE COUNCILS IN MARINE EXTRACTIVE RESERVES IN THE BRAGANTINA REGION OF THE STATE OF PARÁ}

\section{ABSTRACT}

The present work aims to analyze and compare the functioning of the deliberative councils of the Marine Extractive Reserves (Resexs) Caeté-Taperaçu and Araí-Peroba, based on some territorial governance criteria. The study was carried out in the Resexs Marinhas Caeté-Taperaçu (municipality of Bragança) and Araí-Peroba (municipality of Augusto Corrêa), created in 2005, in the northeastern region of the state of Pará. The work was elaborated from a qualitative approach. Data collection took place through questionnaires and semi-structured interviews. It was noted that despite the difficulties, the deliberative council of the marine Resex Caeté-Taperaçu is functioning, although in a centralized and inefficient management. The Araí-Peroba marine Resex deliberative council has been inactive since 2014. The reasons were: the lack of decentralized management, the difficult access to Resex, understanding the meaning of a Resex, strong assistance and party politics. It is concluded that although territorial governance is a social innovation for the management of the territories of marine Resexs, the Caeté-Taperaçu and Araí-Peroba deliberative councils lack governance, since weakened institutional arrangements and ineffective community participation were identified extractivists in the decision process.

\footnotetext{
${ }^{1}$ Mestre em Agricultura Familiar e Desenvolvimento Sustentável pela UFPA, Belém. ivanildeivi@gmail.com.

${ }^{2}$ Doutor em Agro-economia, CIRAD UMR Tetis, professor associado no INEAF da UFPA, Belém. marc.piraux @ cirad.fr.
} 
Keywords: Territorial Governance, Marine Extractive Reserve, Deliberative Council.

\section{INTRODUÇÃO}

As Reservas Extrativistas (RESEX) foram instituídas como uma das categorias de unidade de conservação, a partir da lei $\mathrm{n}^{\circ}$ 9.985, de 18 de junho de 2000 - Sistema Nacional de Unidades de Conservação (SNUC) - que estabelece os critérios e normas para a criação, implantação e gestão das unidades de conservação no Brasil. Os objetivos das RESEX são a proteção dos meios de vida, a cultura das populações tradicionais e o uso sustentável dos recursos naturais (Brasil, 2000).

As RESEX são geridas por conselhos deliberativos através da gestão participativa, com representantes de órgãos públicos, de organizações da sociedade civil organizada e das populações tradicionais, que possibilita debates e diálogos sobre os problemas relacionados às RESEX e à territorialização das políticas públicas. Na visão de Rêgo (2016), os conselhos deliberativos são importantes ferramentas para gestão participativa, ao promover espaços de diálogo entre atores sociais e governamentais. Essa articulação pode garantir direitos, ampliar o conhecimento de desenvolvimento social e do papel do Estado, mas principalmente a busca de um novo paradigma de gestão (Gonçalves; Kauchakje; Moreira, 2015).

Segundo Teisserenc (2014), a gestão participativa nos conselhos deliberativos deve envolver ações coletivas para chegar ao consenso do estabelecimento de regras que venham ser favoráveis tanto para a população extrativista quanto para o meio ambiente, e assim estabelecer regras que sejam capazes de promover a cooperação dos atores governamentais e sociais. No entanto, Cunha e Loureiro (2009) descrevem que é preciso atentar-se aos artifícios que às vezes estão presentes nos planos de manejo, projetos e programas com rótulos democráticos, visto que esses podem ser meios de impor interesses particulares em detrimento aos interesses das populações extrativistas.

Segundo Peres (2011), essa prática é muito recorrente nos conselhos deliberativos, visto que, na maioria das vezes, as participações das populações tradicionais e seus saberes são poucos evidenciados. Daí a importância em analisar o funcionamento da gestão desses conselhos, através do dispositivo de governança territorial, visto que estes representam um espaço de participação e relação de poder entre os atores de diferentes instâncias. Nesse contexto, esta pesquisa foi realizada nos conselhos deliberativos das RESEX marinhas Caeté-Taperaçu e Araí-Peroba, sendo o principal espaço coletivo de tomada de decisão dessas unidades.

\section{GOVERNANÇA TERRITORIAL NOS CONSELHOS DELIBERATIVOS DAS RESEX MARINHAS}

Os autores Teisserenc (2014) e Pires et al. (2011) trazem a ideia de governança territorial como um dispositivo capaz de produzir ações locais eficazes, a fim de promover o engajamento dos 
atores, pois reflete em mobilizar atores sociais para coproduzirem ações coletivas e regras que sejam capazes de facilitar a cooperação de um determinado território e possibilitar a participação da sociedade civil no âmbito político, visto que a governança proporciona ambientes de partilha que envolve o planejamento de ações com atores articulados. Para Cançado, Tavares e Dallabrida (2013), essa articulação entre os atores é normatizada de acordo com os seus arranjos, a exemplos, dos arranjos produtivos locais, conselhos gestores, fóruns temáticos e outros. Contudo, segundo os autores, as relações simbólicas, institucionais e materiais vão de acordo com os seus territórios.

Dallabrida (2011, p. 03) afirma que a governança territorial se refere "[...] às iniciativas ou ações que expressam a capacidade de uma sociedade organizada territorialmente para gerir os assuntos públicos, a partir do envolvimento conjunto e cooperativo dos atores sociais, econômicos e institucionais". No caso específico das RESEX marinhas, os conselhos deliberativos promovem a governança territorial que segundo Teisserenc (2014), constituem a ferramenta adotada pelo Estado para atender às reivindicações dos movimentos sociais com o intuito de uma gestão participativa. Rêgo (2016) também destaca a importância desses conselhos ao descrever como ferramenta de gestão das RESEX, uma vez que são configurados como espaços de diálogos que permitem a participação dos atores sociais.

As competências dos conselhos deliberativos são: criar as regras de funcionamento das RESEX, fiscalizar, gerir as políticas públicas e construir os planos de gestão e manejo (Teisserenc, 2016). Ainda segundo o autor, os conselhos deliberativos apresentam mobilizações constantes, com atores sociais locais engajados e motivados, ao trabalhar ações coletivas na busca de respostas às exigências para o desenvolvimento sustentável. Costa et al. (2017) também expõem que a governança territorial nas RESEX remete à ideia de um território que mobilizou vários atores na busca do desenvolvimento sustentável, ao atuar em cima das ações coletivas multissetoriais para estabelecer as regras comuns capazes de promover a cooperação.

Nos conselhos deliberativos, um dos princípios fundamentais é a participação, que é entendida como forma de influência individual ou coletiva nos processos de decisões; nesse contexto, Bordenave (2013) descreve que é uma necessidade importante dos cidadãos, principalmente como instrumento para solução de problemas. Gohn (2011) também entende que a busca pelos direitos sociais e por cidadania se dá através da participação.

Sob essa ótica, Bordenave (2013) define a participação como um processo de desenvolvimento da consciência crítica e a capacidade do indivíduo de intervir sobre determinado fato. Ainda segundo o autor, o significado de participação se dá pelo seguinte entendimento: “fazer parte" e "tomar parte". De acordo com essas expressões é possível fazer a diferença entre participação passiva e ativa, pois "fazer parte" não necessariamente significa ter voz na tomada de decisão, já "tomar parte" apresenta maior qualidade na participação. Na participação social, o 
engajamento e a mobilização são fundamentais no processo de tomada de decisão, que reflete nas políticas públicas sociais, econômicas e ambientais das RESEX marinhas.

Por isso Teisserenc (2014) expõe que essa participação social dispõe de representantes das comunidades para defender interesses e projetos. Logo, Gohn (2011) ressalta que essa participação não representa apenas um sujeito social, mas toda uma construção de relação entre Estado e a sociedade, mobilizados e participativos na formulação e implementação de uma política pública.

Outro princípio importante nos conselhos deliberativos se trata da aprendizagem dos atores, que, segundo Coudel, Tonneau e Piraux (2010), precisa ter uma capacidade de interação para compartilhar conhecimentos nas questões relacionadas à realização, gestão e habilidades práticas para implementar e gerenciar projetos. Os autores descrevem que a aprendizagem é motivada por um "estímulo", com atores integrados na busca de uma aprendizagem coletiva. No entanto, essa aprendizagem coletiva entre os atores acontece através da gestão compartilhada que existe ou deveria existir nesses conselhos deliberativos, de forma que, por meio desses espaços, é possível a troca de conhecimento entre diferentes atores sobre as RESEX marinhas. Daí, a importância de considerar a governança territorial com um processo de co-construção de arranjos, de conhecimento e de parceria (Coudel; Tonneau; Piraux, 2010).

Para Silva Junior et al. (2018), a gestão compartilhada é uma maneira em que se confrontam diferentes interesses e visões com relação ao território. Por isso, os autores expõem que através dessa forma de gestão é possível assegurar valores e representações, contudo, isso não significa que estejam isentos de conflitos, mas que sejam adotadas estratégias em suas negociações para que as tomadas de decisões possam ser de forma consensual. E, por se tratar de RESEX marinhas, logo seus conselhos deliberativos voltam-se para uma gestão coletiva dos bens comuns.

Contudo, nesses espaços de deliberações, ocorrem diversos conflitos, pois são compostos por distintos atores, logo são pensamentos e interesses diferentes. Para Brito (2008), no Brasil os conflitos surgem no gerenciamento e manejo dos recursos naturais das RESEX, quando atores sociais defendem lógicas diferentes dos atores governamentais na gestão coletiva dos bens comuns. No entanto, para o autor, nem sempre os conflitos são negativos, visto que, através dos conflitos, é possível encontrar formas de entendimento e crescimento na hora de negociar, além de buscar soluções para os problemas existentes, pois é necessário que exista uma visão interdisciplinar dos problemas que envolvem as RESEX marinhas.

Brito (2008) descreve que as políticas públicas são os principais motivos dos conflitos entre as populações locais e a gestão das RESEX, devido serem criadas e implantadas no sistema topdown, com pouca ou nenhuma participação da população que reside nas RESEX. Além de outros motivos relatados pelo autor que dão origem aos conflitos, tais como: a forma como são criadas as 
RESEX, a extensão da área, elaboração do plano de manejo, a localização da unidade de conservação e a forma de conduzir a gestão dos conselhos deliberativos.

Diante dessa realidade, Canto et al. (2018) descrevem que, para que haja uma gestão democrática nos territórios de RESEX, é necessário medir os conflitos, isso não significa que sejam extinguidos, visto que os conflitos têm um viés de crescimento para os conselheiros e um desenvolvimento para o território, uma vez que a eliminação do conflito, pode ocasionar um retrocesso do território.

\section{METODOLOGIA}

A pesquisa foi realizada a partir de dados secundários para compreender sobre governança territorial em RESEX marinhas e dados primários a partir de estudo de caso em duas RESEX marinhas que estão localizadas na região bragantina do estado do Pará. A primeira denominada de RESEX marinha Caeté-Taperaçu, que pertence ao município de Bragança, e a segunda RESEX marinha é a Araí-Peroba, localizada no município de Augusto Corrêa. A figura (01) apresenta um mapa com a localização das RESEX marinhas e seus respectivos municípios.

Figura 1: Mapa de localização das RESEX marinhas Caeté-Taperaçu e Araí-Peroba.

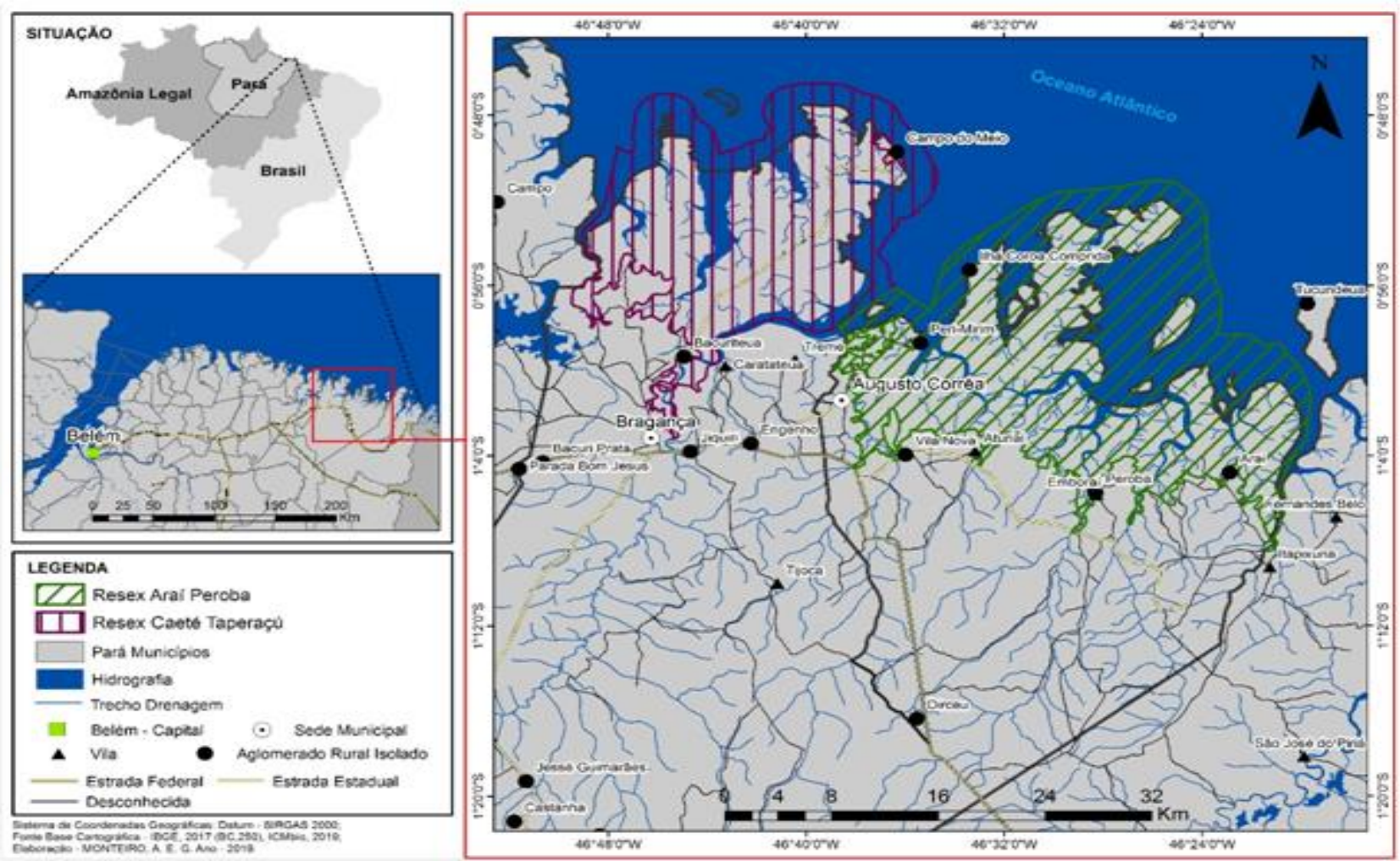

Fonte: Pesquisa Elaboração: Espírito Santo e Monteiro (2019)

A escolha em estudar essas RESEX marinhas se deu pelo fato de estarem geograficamente próximas na região bragantina, o que possibilita maior flexibilidade à pesquisa; estas possuem algumas similaridades, como o ano que foram consolidadas como RESEX (2005) e o ano da criação 
de seus respectivos conselhos deliberativos (2007); além de analisar e comparar o funcionamento dos conselhos deliberativos das duas RESEX marinhas, pois tais conselhos também apresentam diferenças, a exemplo da existência de um plano de manejo da RESEX Caeté-Taperaçu (o que pressupõe um processo mais avançado) e a ampliação espacial da RESEX Araí-Peroba.

Outra questão pela escolha das RESEX é o desenvolvimento do funcionamento dos conselhos deliberativos, pois em uma RESEX (Caeté-Taperaçu) o conselho nunca deixou de funcionar, já na outra RESEX (Araí-Peroba) se encontra inativo desde 2014. Além do fato de que, mesmo estando geograficamente próximas, na RESEX do município de Bragança existem diversas pesquisas publicadas sobre a mesma, assim como o funcionamento do seu conselho; enquanto que sobre a outra RESEX há pouca pesquisa. Isso se dá devido ao difícil acesso a essa RESEX, com estradas ruins, pontes quebradas e a dificuldade em encontrar extrativistas com informação sobre o funcionamento da gestão dessa unidade de conservação.

A coleta dos dados primários aconteceu entre os meses de abril a novembro de 2019, com a realização de entrevistas com questionários semiestruturados direcionados aos conselheiros e exconselheiros das duas RESEX marinhas. As entrevistas contaram com a participação de 22 pessoas, sendo elas representantes de órgãos públicos, sociedade civil organizada e população extrativista (quadro 01).

Quadro 1: Descrição dos conselheiros e ex-conselheiros que foram entrevistados.

\begin{tabular}{|c|c|c|l|}
\hline CONSELHEIROS & $\begin{array}{c}\text { RESEX } \\
\text { CAETÉ- } \\
\text { TAPERAÇU }\end{array}$ & $\begin{array}{c}\text { RESEX } \\
\text { ARAÍ- } \\
\text { PEROBA }\end{array}$ & $\begin{array}{l}\text { INSTITUIÇÕES, ORGANIZAÇÕES E POLOS DAS RESEX } \\
\text { MARINHAS }\end{array}$ \\
\hline Governamentais & 03 & 03 & $\begin{array}{l}\text { ICMBio; Empresa de Assistência Técnica e Extensão Rural } \\
\text { (EMATER); e Prefeituras Municipais. }\end{array}$ \\
\hline $\begin{array}{c}\text { Sociedade civil } \\
\text { organizada }\end{array}$ & 03 & 03 & $\begin{array}{l}\text { Sindicado dos Trabalhadores Rurais (STR); Sindicado dos } \\
\text { Pescadores Artesanais (SPA); e as Associações dos usuários } \\
\text { das RESEX marinhas. }\end{array}$ \\
\hline $\begin{array}{c}\text { População } \\
\text { extrativista }\end{array}$ & 07 & 03 & $\begin{array}{l}\text { Os polos da RESEX Caeté-Taperaçu (Bacuriteua, Acarajó, } \\
\text { Ajuruteua, Campo, Tamatateua, Caratateua e Treme). } \\
\text { Os polos da RESEX Araí-Peroba (Arai, Peroba e Porto do } \\
\text { Campo). }\end{array}$ \\
\hline
\end{tabular}

Fonte: Elaborado pelos autores.

Para analisar os dados, utilizou-se alguns critérios, tais como: participação dos atores; gestão compartilhada, os produtos da governança territorial na atuação dos conselhos deliberativos; e os resultados do funcionamento da gestão dos conselhos deliberativos. O objetivo é fazer uma análise entre os conselhos das RESEX estudadas a partir desses critérios. O quadro 02 apresenta mais detalhado os assuntos utilizados. 
Quadro 02: Matriz de análise para os conselheiros e ex-conselheiros.

\begin{tabular}{|c|c|c|c|}
\hline Critérios & Assuntos abordados & Objetivos & Autores \\
\hline Participação & $\begin{array}{l}\text { - Engajamento dos conselheiros } \\
\text { - Interação entre os conselheiros }\end{array}$ & $\begin{array}{l}\text { Analisar a participação dos } \\
\text { conselheiros sociais e } \\
\text { governamentais nos conselhos, } \\
\text { sob a ótica do engajamento e } \\
\text { interação. }\end{array}$ & $\begin{array}{lr}\text { Bordenave } & (2013) ; \\
\text { Gohn } & (2011) ; \\
\text { Teisserenc } & (2014) ; \\
\text { Costa et al. (2017). }\end{array}$ \\
\hline $\begin{array}{c}\text { Gestão } \\
\text { compartilhada }\end{array}$ & $\begin{array}{l}\text { - Cooperação } \\
\text { - Parceiras entre os conselheiros e } \\
\text { as instituições. } \\
\text { - Conflitos existentes nesses } \\
\text { espaços de deliberações. }\end{array}$ & $\begin{array}{l}\text { Analisar a gestão dos conselhos, } \\
\text { em relação à cooperação, } \\
\text { parcerias e conflitos existentes } \\
\text { nesses espaços de deliberações. }\end{array}$ & $\begin{array}{l}\text { Silva Junior et al. } \\
\text { (2018); Dallabrida } \\
(2011) \text {; Pires et al. } \\
\text { (2011); Brito (2008). }\end{array}$ \\
\hline $\begin{array}{l}\text { Produtos da } \\
\text { governança } \\
\text { territorial }\end{array}$ & $\begin{array}{l}\text { - Existência de planos } \\
\text { - Existência de políticas públicas } \\
\text { adaptadas. }\end{array}$ & $\begin{array}{l}\text { Analisar o que foi coproduzidos } \\
\text { nos conselhos. }\end{array}$ & Teisserenc, (2016). \\
\hline $\begin{array}{l}\text { Resultados do } \\
\text { funcionamento da } \\
\text { gestão dos } \\
\text { conselhos } \\
\text { deliberativos }\end{array}$ & $\begin{array}{l}\text { - Eficiência do funcionamento } \\
\text { dos conselhos deliberativos. } \\
\text { - Legitimidade. } \\
\text { - Aprendizagem. }\end{array}$ & $\begin{array}{l}\text { Analisar o que os conselhos } \\
\text { obtiveram como resultado ao } \\
\text { longo de seus funcionamentos, } \\
\text { com relação à eficiência, } \\
\text { legitimidade e aprendizagem. }\end{array}$ & $\begin{array}{l}\text { Coudel, Tonneau e } \\
\text { Piraux (2010). }\end{array}$ \\
\hline
\end{tabular}

Fonte: Elaborado pelos autores.

\section{O FUNCIONAMENTO DOS CONSELHOS DELIBERATIVOS NAS RESEX MARINHAS CAETÉ-TAPERAÇU E ARAÍ-PEROBA, NA REGIÃO BRAGANTINA}

Nos conselhos deliberativos das RESEX marinhas Caeté-Taperaçu e Araí-Peroba, o presidente (ICMBio) e o vice-presidente (associações) possuem a responsabilidade de garantir a participação dos demais conselheiros na elaboração das regras tanto interna dos conselhos, como as de uso comum das RESEX marinhas, para serem efetivas na prática; já os conselheiros representantes dos polos são responsáveis pela elaboração, avaliação e execução dos planos, ações e atividades; e os demais conselheiros são representantes dos órgãos públicos, sejam eles federais, estaduais e municipais, bem como os conselheiros das entidades sociais são co-responsáveis pela elaboração, avaliação e execução das regras. O que Medeiros (2009) descreve como uma nova perspectiva de controle do uso dos recursos naturais e a descentralização de gestão.

Participação dos conselheiros

O ICMBio começa a exercer seu papel com maior efetividade no conselho da RESEX Caeté-Taperaçu a partir de 2010, período que o escritório do órgão se instala no município de Bragança. Já no conselho da RESEX Araí-Peroba, essa efetividade começa só a partir de 2017, com objetivo de reativar tal conselho. O Instituto Nacional de Colonização e Reforma Agrária (INCRA) e as prefeituras municipais nos dois conselhos atuaram mais nas questões de infraestruturas. Já com relação aos processos de elaboração das regras internas, estes aturam de forma coadjuvante, haja vista que não participaram diretamente. 
A Câmara de Vereadores, apesar de ter o papel de apoiar e incentivar as atividades e verbas destinadas às RESEX marinhas, foi pouco atuante nos dois conselhos. Embora tivessem pessoas que foram eleitas vereadores e prefeitos municipais, existe um descontentamento por parte das populações extrativistas nas RESEX marinhas sobre os ex-conselheiros que assumiram cargos políticos municipais.

A Empresa de Assistência Técnica e Extensão Rural (EMATER), Universidade Federal do Pará (UFPA), Secretaria Estadual de Meio Ambiente (SEMA), Sindicato dos Pesquisadores Artesanais (SPA) e Sindicato dos Trabalhadores Rurais (STR) foram e são pouco atuantes no conselho da RESEX Caeté-Taperaçu, principalmente no conselho da RESEX Araí-Peroba, que não houve participação nenhuma desses órgãos.

A Associação dos Usuários da Reserva Extrativista Marinha Caeté-Taperaçu (Assuremacata) e a Associação dos Usuários da Reserva Extrativista Marinha Araí-Peroba (AUREMAP) atuaram de forma assídua no desenvolvimento das atividades dos conselhos. Contudo, na RESEX Caeté-Taperaçu, por motivos de partidarismo político, a Assuremacata perdeu a credibilidade diante dos seus associados, o que levou a um enfraquecimento no desempenho do seu papel. Já a AUREMAP, por ser a responsável em conduzir tudo na RESEX Araí-Peroba, acarretou em uma gestão centralizada; contradizendo todos os quesitos expostos por Costa et al. (2017), Teisserenc (2014), Medeiros (2009) e Gohn (2011) sobre participação, engajamento, gestão compartilhada e engajamento.

Quanto aos conselheiros dos polos na RESEX Caeté-Taperaçu, apesar de atualmente estarem desmotivados por não concordarem da forma como o ICMBio conduz o gerenciamento da RESEX, já estiveram articulados e mobilizados no desenvolvimento de seus papéis. Quesito que faltou nos conselheiros dos polos na RESEX Araí-Peroba, uma vez que foram pouco atuantes com o desenvolvimento de seus papéis, haja vista que o conselho não foi capaz de construir engajamento, voluntarismo e uma consciência de coletividade.

Quadro 3: Diferenças sobre o critério de participação nas RESEX pesquisadas.

\begin{tabular}{|c|c|c|}
\hline $\begin{array}{l}\text { Assuntos abordados } \\
\text { sobre a participação }\end{array}$ & RESEX Caeté-Taperaçu & RESEX Araí-Peroba \\
\hline Engajamento & $\begin{array}{l}\text { Há um enfraquecimento no engajamento dos } \\
\text { conselheiros, principalmente com relação à } \\
\text { coprodução na elaboração do plano de } \\
\text { manejo da RESEX marinha, sendo um } \\
\text { processo importante na tomada de decisões. }\end{array}$ & $\begin{array}{l}\text { Pelo fato de o conselho não ter sido } \\
\text { atuante na RESEX, não houve } \\
\text { engajamento dos conselheiros } \\
\text { representantes dos polos, da sociedade } \\
\text { civil e órgãos públicos, o que levou à } \\
\text { inatividade desse conselho. }\end{array}$ \\
\hline $\begin{array}{l}\text { Interação entre os } \\
\text { conselheiros }\end{array}$ & $\begin{array}{l}\text { A interação entre os conselheiros existia até } \\
\text { o ano de 2013, quando a Assuremacata } \\
\text { assumia o papel de articulador entre os } \\
\text { conselheiros representantes dos polos. A } \\
\text { partir de } 2014 \text {, essa interação é enfraquecida } \\
\text { devido aos conflitos com a associação. }\end{array}$ & $\begin{array}{l}\text { A responsável em fazer a interação era a } \\
\text { AUREMAP, que recorria aos demais } \\
\text { conselheiros de forma individual. Já } \\
\text { entre os conselheiros representantes dos } \\
\text { polos, não existia interação. }\end{array}$ \\
\hline
\end{tabular}

Fonte: Elaborado pelos autores. 
Identifica-se que, no conselho da RESEX Caeté-Taperaçu, o engajamento e a interação oscilam bastante, haja vista que, entre 2007 e 2009, existia uma maior efetividade dos conselheiros dos polos com relação ao conselho. Em 2010, com a chegada do ICMBio, observa-se uma quebra no sistema de organização entre a Assuremacata e os polos, fazendo um efeito ao contrario, pois o ICMBio deveria fortalecer a dinâmica. A partir de 2014, a participação no conselho encontra-se enfraquecida, devido ao não gerenciamento dos conflitos e falhas nas missões dos atores sociais e governamentais. O que também ficou evidentes nas pesquisas de Silva Junior et al. $(2014 ; 2018)$, nessa RESEX.

Outro fato que contribuiu para a situação atual desse conselho foi a saída de muitos conselheiros dos polos, que participavam desde a criação do conselho deliberativo e que abandonaram seus cargos devido ao fato de não concordarem com a nova forma de gerenciamento do conselho, e os novos conselheiros que assumiram já vieram com a visão de que a RESEX não é apenas como um território de comunidades extrativistas e proteção ao meio ambiente, mas sim um território onde se pode obter vantagens políticas, como assumir cargos políticos. Além da falta de projetos da universidade que tem um papel central para valorização dos saberes e práticas nativas.

Já no conselho da RESEX Araí-Peroba, tanto o engajamento como a interação nunca foram efetivos na prática. Isso aconteceu devido a uma série de fatores, entre eles cita-se: o difícil acesso à RESEX; os conflitos políticos entre os conselheiros e a gestão municipal; e a visão dos extrativistas de que a RESEX é uma política pública assistencialista, quando deveria ser ambiental. Identifica-se que tais fatos aconteceram devido à falta do exercício da coletividade, do bem comum, e da RESEX como unidade de conservação, de forma que os interesses individuais estão acima dos interesses coletivos. Essas questões foram identificadas desde 2005 na criação da RESEX, no ano de 2014, com a sua ampliação e, em 2019, com a reativação do conselho.

\section{Gestão Compartilhada}

Quanto à gestão compartilhada nos conselhos deliberativos, de acordo com as normas constitucionais, é dever do Estado e da sociedade civil defender e preservar o meio ambiente, visto que cabe ao poder público, implementar políticas públicas destinadas à preservação e conservação do meio ambiente, enquanto que a sociedade civil tem o dever de controlar e avaliar as políticas públicas. 
Quadro 4: Diferenças sobre o critério de gestão compartilhada nas RESEX pesquisadas.

\begin{tabular}{|c|c|c|}
\hline Assuntos abordados sobre a & RESEX Caeté-Taperaçu & RESEX Araí-Peroba \\
\hline Cooperação & $\begin{array}{l}\text { A cooperação na gestão do conselho } \\
\text { deliberativo apresenta-se atualmente } \\
\text { enfraquecida. No entanto, quando tal } \\
\text { cooperação existia, era limitada entre os } \\
\text { conselheiros representante dos polos, do } \\
\text { ICMBio e da Assuremacata. }\end{array}$ & $\begin{array}{l}\text { A cooperação no conselho deliberativo } \\
\text { só existia no período do } \\
\text { desenvolvimento das políticas públicas. } \\
\text { A partir do momento que as políticas } \\
\text { foram extintas, isso levou ao } \\
\text { enfraquecimento da cooperação. }\end{array}$ \\
\hline Parceiras & $\begin{array}{l}\text { O conselho deliberativo possui parcerias } \\
\text { com a Rare e com os comitês } \\
\text { comunitários. }\end{array}$ & Não tinha parcerias. \\
\hline Conflitos & $\begin{array}{l}\text { Ausência de órgãos públicos (prefeitura, } \\
\text { INCRA, EMATER e marinha do Brasil); } \\
\text { plano de manejo elaborado de forma } \\
\text { tecnicista e centralizado; falta de } \\
\text { comunicação entre os conselheiros; } \\
\text { desvios de verbas federais; a escolha dos } \\
\text { beneficiários dos programas sociais; } \\
\text { política partidária; e a falta de atuação da } \\
\text { Assuremacata. }\end{array}$ & $\begin{array}{l}\text { Ausência de órgãos públicos (prefeitura, } \\
\text { ICMBio, INCRA, EMATER, } \\
\text { universidades e marinha do Brasil); falta } \\
\text { de comunicação entre os conselheiros; a } \\
\text { pesca predatória, a não definição clara } \\
\text { das regras estabelecidas; a escolha dos } \\
\text { beneficiários dos programas sociais; e a } \\
\text { política partidária. }\end{array}$ \\
\hline
\end{tabular}

Fonte: Elaborado pelos autores.

A gestão compartilhada no conselho da RESEX Caeté-Taperaçu encontra-se enfraquecida devido a uma série de conflitos que foram se perpetuando ao longo dos anos. A cooperação existia até o ano 2014 nas atividades para implementação dos planos, ações e projetos, contudo era limitado aos conselheiros representantes dos polos, ICMBio e a Assuremacata, os demais ficavam ausentes. Os entrevistados relatam que os conflitos sobre a política partidária entre os conselheiros dos polos resultaram nesse enfraquecimento da gestão, o que confirmou Silva Junior (2013).

O conflito da política partidária não se resolveu até hoje, tivemos que engolir essa questão, porque havia muitos conselheiros que eram coniventes. A política é um ciclo vicioso e os próprios comitês começaram a aceitar, porque no caso eram os próprios conselheiros dos polos que comprava voto para o prefeito e deputados (Ex-conselheira do polo Tamatateua, 2019).

O fato é que o conselho deliberativo depende muito do apoio do poder público, e aqui na Caeté-Taperaçu existe uma coisa muito forte, chamado partidarismo, se fulano é de um lado, então ele não vai ajudar porque o outro não apoia o candidato dele. E foi isso que aconteceu para o conselho deliberativo chegar no estado que ele se encontra hoje em dia (Conselheiro do polo Caratateua, 2019).

Por sua vez, a situação sobre a gestão compartilhada no conselho da RESEX Araí-Peroba não era muito diferente, tal conselho apresenta carência de parcerias, de cooperação e falta de comunicação entre os conselheiros. É notório que em ambos os conselhos os seus funcionamentos são marcados por constantes conflitos, os mais frequentes foram de cunho político e social. Sobre esses conflitos, Losekann (2012) descreve três explicações: dificuldade de priorizar as exigências ambientais quando contradizem os interesses econômicos; caráter consultivo, quando deveriam ser deliberativos, e a baixa qualidade das deliberações.

De fato, questões que foram observadas nos dois conselhos pesquisados, apesar de terem caráter deliberativo na teoria, na prática apresenta-se mais de caráter consultivo, logo não 
apresentam um local de discussão de diferentes opiniões, o que limita a gestão compartilhada, tanto no âmbito da decisão como de cooperação e parceiras. Um exemplo disso, é que na maioria das vezes quem construía ou constrói as pautas das reuniões, em um conselho, era o ICMBio, e, no outro, era a AUREMAP. De modo que os conselheiros dos polos e as outras instituições apenas estavam presentes nas reuniões para aprovar ou reprovar decisões já pré-estabelecidas. Por isso Cunha e Loureiro (2009) faz o alerta nas propostas com rótulos democráticos, o que na verdade é apenas impor interesses particulares, quando deveriam ser coletivos.

Identifica-se que em ambos os conselhos não conseguiram gerenciar seus conflitos e com isso veio o enfraquecimento de um e a inatividade do outro. Questões que Arns (2009) descreve que, em uma instância de governança, sempre haverá disputas de interesses e conflitos, contudo é necessário lidar com os conflitos para que os mesmos não venham interferir no desenvolvimento do funcionamento dos conselhos.

Uma RESEX é instrumento de política pública que deve ter como base o reconhecimento das competências das populações tradicionais, que são exercidas através de seus saberes e práticas. Entretanto, devido à onipresença de práticas político-partidárias levaram à perda de vitalidade nas atividades das duas RESEX. Nos dois casos, ocorreram os mesmos efeitos: déficit de participação, problemas com confiança na qualidade das informações, falta de trasnparência, predominância das práticas assistencialistas e o descaso relativo à noção de bens comuns, entre outros.

Saídas (outputs) dos produtos da governança territorial

Observa-se que, no conselho da Resex Caeté-Taperaçu, houve maior coprodução com relação aos planos (de utilização e gestão), com 03 (três) planos de gestão nos anos 2010, 2014 e 2017, que teve a participação na elaboração do ICMBio, Assuremacata, conselheiros dos polos e alguns conselheiros de entidades sociais; 01 (um) diagnóstico de elaboração do plano de manejo em 2012, que teve a participação do ICMBio, Assuremacata e os conselheiros dos polos (apesar dessa Resex ter um plano de manejo, os extrativistas não classificam que tal plano foi coproduzido, visto que sua construção foi centralizada e tecnicistas); e diversas ações coletivas, que vão desde o levantamento de dados dos usuários da RESEX, até o reflorestamento de uma área na vila chamada "Que Era", que antes era uma plantação de arroz.

Além de uma política pública adaptada, a exemplo das casas habitacionais construídas nas comunidades pertencentes ao polo Ajuruteua, nesse polo, partes das comunidades extrativistas estão localizadas em áreas de praias, e, por esse motivo, as casas foram construídas de madeiras e não de alvenaria, como estava no projeto, sendo os próprios moradores das comunidades junto ao conselheiro do polo que construíram as primeiras casas. 
Já o conselho da RESEX Araí-Peroba teve apenas 01 (um) plano de gestão, em 2010, elaborado pela AUREMAP, junto aos conselheiros dos polos; a elaboração do plano de manejo, em 2010, elaborado por uma equipe técnica do ICMBio, junto com a AUREMAP, e os conselheiros dos polos; e 01 (um) diagnóstico para ampliação da RESEX em 2013, elaborado pelo ICMBio em parceria com a AUREMAP. A partir das entrevistas com os ex-conselheiros, foi possível identificar um avanço com relação à infraestrutura nas áreas da RESEX, contudo, ao conhecer algumas comunidades, observou-se algumas falhas, tais como: alguns ramais não foram concluídos, pontes não terminadas, estradas construídas dentro de área de mangue, algumas casas construídas sem banheiros e sem o acabamento final.

A diferença na produção nas duas RESEX se dá pelas questões de maior incidência de participação, mobilização e engajamento dos conselheiros dos polos e entidades sociais, além das parcerias com universidades e organizações sociais e públicas, que teve no conselho da RESEX Caeté-Taperaçu e que faltou no conselho da RESEX Araí-Peroba.

Resultados (outcomes) do funcionamento dos conselhos deliberativos

Com relação aos resultados (outcomes) do funcionamento do conselho da RESEX CaetéTaperaçu, sobre a eficácia nas políticas públicas, algumas tiveram êxito, a exemplo das casas habitacionais. Já com relação à eficiência nas regras estabelecidas nos planos de manejo e gestão, os entrevistados relatam que tal eficiência só ocorreu nos planos de gestão, pois no plano de manejo muitas das regras não estão de acordo com as realidades das comunidades extrativistas e, em decorrência disso, não são cumpridas pelos extrativistas.

Quanto à legitimidade, entre o ano de 2005 e 2013 as comunidades extrativistas reconheciam o conselho como um espaço para solucionar seus problemas, principalmente os sociais, visto que havia muitas demandas das comunidades, e grande parte dessas demandas eram atendidas. No entanto, atualmente os entrevistados expõem que para as comunidades extrativistas o conselho e a própria RESEX acabaram.

Quanto à aprendizagem coletiva dos conselheiros dos polos e entidades sociais ao longo do funcionamento do conselho, os entrevistados informaram que 55\% obtiveram uma visão mais clara dos desafios da RESEX, principalmente com relação ao planejamento, implementação e avaliação dos planos e projetos que foram desenvolvidos; $36 \%$ aprenderam a negociar e dialogar com o poder público; e apenas 9\% tiveram trocas de experiências e conhecimentos entre si.

Já no conselho da RESEX Araí-Peroba, a eficácia em seu funcionamento deixou a desejar, seja com relação às políticas públicas e infraestrutura, ou com relação a regras estabelecidas no plano de gestão e de uso comum da RESEX, uma vez que tais regras não foram efetivas na prática. Esse conselho, desde a sua criação em 2007, não foi legitimado, devido a sua pouca atuação, por 
isso a AUREMAP era mais reconhecida como um espaço para solucionar os problemas do que o próprio conselho, o que levou para uma pouca aprendizagem coletiva entre os conselheiros.

Em síntese, é possível observar que, nos conselhos deliberativos pesquisados, os princípios da tomada de decisão coletiva, dialogicidade, transparência nos processos decisórios, entendimento e emancipação estão deixando a desejar. Haja vista que a emancipação não aconteceu no conselho da RESEX Araí-Peroba, pois, com o término das políticas públicas, os conselheiros dos polos foram se desmobilizando, o que identifica um forte assistencialismo.

\section{PARTICIPAÇÃO COMUNITÁRIA NA GESTÃO COLETIVA EM TERRITÓRIO DE USO COMUM}

Ao analisar o funcionamento do conselho da RESEX Caeté-Taperaçu, percebe-se que houve, de certa forma, uma participação da população extrativista quanto à construção das regras do plano de utilização, além de alguns questionamentos e conflitos sobre regras estabelecidas no plano de manejo, que também foi identificado por Silva Júnior et al. (2014). Haja vista que foram decididas de forma centralizada, por não levar em consideração a opinião dos extrativistas e pelo fato do documento está em uma linguagem técnica. Peres (2011) descreve que não basta apenas deixar a linguagem acessível para que termos técnicos usados sejam entendidos e compreendidos. É necessário construir o diálogo com a população, com base nos diferentes saberes, uma vez que há diferenças entre o olhar técnico sobre os recursos naturais e o olhar compartilhado pelas populações tradicionais.

\footnotetext{
A gente queria muito que fosse criado como a gente discutiu com os pescadores, mas quando olhamos o documento estava tudo em uma linguagem técnica. O que chateou bastante, porque queríamos que ficasse um vocabulário que a gente entendesse, de acordo com os nossos conhecimentos, afinal era um plano que seria nosso, então deveria está falando a nossa língua. (Ex-conselheira do polo Tamatateua, 2019).
}

No conselho da RESEX Araí-Peroba, faltou efetividade e participação da população extrativista, haja vista que faltou representação e repasse de informação para os extrativistas, pois muitos não sabem o significado de uma RESEX e muito menos que residem dentro de uma. Esse fato aconteceu devido a essa RESEX ter sido ampliada em um sistema top-down, levando em consideração apenas interesses políticos como meio de obter votos, através de promessas à população extrativista que nunca foram cumpridas. Quando deveria ter acontecido através do bottom-up, logo, um desejo da própria população extrativista de que houvesse a ampliação da RESEX.

Nesse conselho, observam-se questões pontuadas por Olson (1965) com relação aos free riders, caracterizado por pouco voluntarismo na preservação e produção dos bens comuns, visto que os interesses individuais estavam acima dos interesses coletivos, exemplo disso foram as grandes 
áreas desmatadas devido a um fenômeno que aconteceu, chamado de êxodo urbano, em que as pessoas da cidade estavam indo para a área da RESEX em busca de benefícios sociais, e isso acarretou na super-exploração, devido às regras não terem sido bem definidas. Nessa RESEX, o plano de manejo não chegou a ser aprovado, contudo sua elaboração também foi bem criticada devido às diversas regras construídas em cima de saberes técnicos, ignorando assim os saberes tradicionais. Questões que contrariam o ponto de vista de Ostrom (1990), visto que, segundo a autora, para existir uma gestão coletiva eficiente, é necessário que as regras e mecanismos sejam estabelecidos e implementados com a participação do maior número de atores possível.

A Resex marinha vai dar uma rede e uma canoa para o cara pescar, também vai dar
geladeira, fogão, energia, uma estrada, então essa parte é boa, porque ela vai suprir as
necessidades, mais aí vamos ter que assumir uma responsabilidade de uma série de regras
que os caras não estão acostumados a trabalhar, são tantas regras que às vezes é quase
impossível de cumprir (Liderança extrativista da vila de Nova Olinda, 2019).

Com a implantação das RESEX, houve algumas regras estabelecidas sem a participação dos extrativistas, chegando apenas prontas para que estes acatassem as regras pré-estabelecidas (os planos de manejos). Com isso, na maioria das vezes as regras não são respeitadas pelas comunidades extrativistas, pois não houve a participação dos que são afetados diretamente com as novas regras. Isso acarretou conflitos, pois o território, antes de ser considerado uma RESEX, é a moradia da população tradicional, no qual já existem suas próprias regras com relação à coleta do caranguejo, ao manejo da pesca e ao extrativismo. Sob essa ótica, Ferreira, Vasconcelos Sobrinhos e Vasconcelos (2017) descrevem um dos maiores conflitos gerados nas RESEX, as regras que são impostas, pois, antes das novas regras, já existia a relação entre o homem e o meio em que vive, logo uma noção de pertencimento, do espaço como seu território.

Essa contradição na elaboração das regras gerou vários conflitos. Por exemplo, na Resex marinha Caeté-Taperaçu, a população extrativista não respeita o plano de manejo por não se sentir representado no plano, devido ao fato de ter sido elaborado em um sistema top-down, quando deveria ser no sistema bottom-up. Sob essa questão, Peres (2011) descreve que existe um empate entre os saberes, de um lado as autoridades ambientais que valorizam os saberes científicos emitidos nas portarias, e do outro as populações que relutam por não serem ouvidas e nem levadas em consideração seus saberes tradicionais.

Eu critiquei muito o plano de manejo, porque nós fizemos uma maratona de discussões nas comunidades extrativistas para falar do plano de manejo, depois que ficou pronto, nós trouxemos uma demanda de informações, para uns caras que vieram para escrever o plano de manejo lá de Brasília, que não entendia nada da nossa realidade (Ex-conselheira representante do polo Tamatateua, 2019).

Essa centralização nas regras contraria o que diz no artigo $3^{\circ}$ da Instrução Normativa do conselho deliberativo, o qual define: que as diretrizes para a elaboração do plano de manejo devem 
ocorrer com a transparência dos processos e adequação a cada realidade; deve ser levado em consideração o reconhecimento, a valorização e o respeito à diversidade socioambiental, cultural e econômica das populações tradicionais; a promoção dos meios necessários adequados para a efetiva participação das populações tradicionais nos processos decisórios e seu protagonismo na gestão (BRASIL, 2007).

\section{CONCLUSÃO}

Os principais fatores que levaram à dificuldade de funcionamento do conselho deliberativo da RESEX Caeté-Taperaçu e à inatividade do conselho da RESEX Araí-Peroba se assemelham: de um lado, disputa de política partidária, desarticulação entre os conselheiros dos polos e as associações, seja por conflitos ou por falta de interesse de participar, seja por interesses pessoais de quem estava à frente das negociações ou pela falta de empoderamento dos conselheiros dos polos. Do outro lado, a falta de apoio de conselheiros dos órgãos públicos, tais como: INCRA, prefeituras, câmaras de vereadores, Marinha do Brasil e as universidades, gestão centralizadora nos conselhos, e a falta de políticas públicas. Logo, entende-se em razão disso a falta de visão dos conselhos e entendimento da missão deles, que contribuiu para falta de construção de uma consciência e ação coletiva.

Nas duas RESEX estudadas, identificou-se que existiu espaço para que os conselheiros dos polos, de entidades sociais e dos órgãos públicos tivessem direito a voz e voto, contudo apenas esses quesitos não os classificam como espaços democráticos. Se o processo de decisão não for descentralizado e feito com transparência, levando em consideração que a gestão nesses espaços é compartilhada, logo exige efetividade na participação dos conselheiros. Outro ponto importante que vale a pena atentar são os rótulos democráticos que os conselhos das RESEX propagam, quando na verdade é apenas uma manipulação para obter objetivos pessoais.

A partir disso, os critérios sobre a gestão dos conselhos deliberativos confirmam que, nos dois conselhos pesquisados, existe falta de transparência na comunicação, visto que observou-se uma desconfiança entre os conselheiros, devido às diversas omissões de informações importantes ao longo do funcionamento da gestão dos conselhos, seja entre os próprios conselheiros ou entre os conselheiros dos polos e as comunidades extrativistas. Além da falta de parcerias, articulação, capacitações e treinamentos para conselheiros, bem como a falta de habilidades na negociação de conflitos e conselhos com caráter consultivo, quando deveria ser deliberativo.

Os conselhos das RESEX Caeté-Taperaçu e Araí-Peroba não colocaram em prática as alternativas dadas por Ostrom (1990) dos arranjos institucionais e a criação das regras internas (planos de gestão) e regras de uso comum (plano de manejo) serem de forma coletiva, além da participação ativa e efetiva, comprometimento, voluntarismo, conscientização ambiental e a 
mobilização. De maneira geral, um dos maiores desafios nos dois conselhos pesquisados, é o gerenciamento de forma coletiva dos recursos comuns dos territórios de RESEX, seja pela falta de compreensão da missão do conselho, ou por não saber lidar com os conflitos.

Logo, carece de uma mudança do funcionamento institucional, voltando-se para valorização dos saberes locais e condições de meios para que as populações rurais possam gerir bens comuns. $\mathrm{O}$ que vai refletir no reconhecimento dos conselheiros quanto à importância da sua participação nas ações e projetos recorrentes nas RESEX, quando estas são elaboradas no sistema bottom-up.

\section{REFERÊNCIAS}

ARNS, P. C. Governança democrática e desenvolvimento territorial: avanços e limites das iniciativas brasileiras. In: ZAPATA, T. (org.). Desenvolvimento local e a nova governança. Recife: IADH, 2009. pág. 79-111.

BORDENAVE, J. E. D. O que é participação? 8 ed. São Paulo: Editora Brasiliense, 2013.

BRASIL. Lei n. 9.985, de 18 de jul de 2000. Sistema Nacional de Unidades de Conservação SNUC. Disponível em: <http://www.mma.gov.br/port/sbf/dap/doc/ snuc.pdf>. Acesso em: $15 / 07 / 2018$.

BRASIL - Instrução Normativa $n^{\circ}$ 02, de 18 de set de 2007. Instituto Chico Mendes de Conservação da Biodiversidade - Disciplina as diretrizes, normas e procedimentos para formação e funcionamento do Conselho Deliberativo de Reserva Extrativista e de Reserva de Desenvolvimento Sustentável. Disponível em: http://www.icmbio.gov.br/portal/images/stories/o-quesomos/in022007.pdf. Acesso em: 13/06/2018.

BRITO, D. M. C. Conflitos em Unidades de Conservação. Revista de Humanidades do Curso de Ciências Sociais. n. 1, dez, 2008.

CANÇADO, A. C.; TAVARES, B.; DALLABRIDA, V. R. Gestão social e governança territorial: interseções e especificidades teórico-práticas. Revista Brasileira de Gestão e Desenvolvimento Regional, vol. 09, n. 03, pág. 313-353, set/dez 2013.

CANTO, O. do et al. Conflitos socioambientais e gestão do território em unidades de conservação na zona costeira do Estado do Pará-Amazônia-Brasil. In: SILVA, C. N. da; OLIVEIRA NETO, A. da C.; SOBREIRO FILHO, J. Perspectiva e analises do espaço geográfico: dinâmicas ambientais e uso dos recursos naturais. Belém: GAPTA/UFPA, 2018. v. 01, pág. 87-114.

COSTA, G. B. et al. Percepção das lideranças sobre governança nas reservas extrativistas do Estado de Rondônia. In: $8^{\circ}$ Seminário Internacional sobre Desenvolvimento Regional: Territórios, Redes e Desenvolvimento Regional: Perspectivas e Desafios. Anais.... Set, Santa Cruz do Sul/RS, pág.0114, 2017.

COUDEL, E.; TONNEAU, J. P.; PIRAUX, M. Articular dispositivos de formação et de governança: Um desafio para o desenvolvimento. Raízes-Revista de Ciências Sociais e Econômicas, vol. 29, n. 01, pág. 143-153, 2010.

CUNHA, C. C.; e LOUREIRO, C. F. B. Reservas extrativistas: limites e contradições de uma territorialidade seringueira. Theomai, n. 20, Pág. 169-1985, 2009.

DALLABRIDA, V. R. Governança territorial e desenvolvimento: as experiências de descentralização político administrativa no Brasil como exemplos de institucionalização de novas escalas territoriais de governança. In: I Circuito de Debates Acadêmicos (CODE). Anais..., 2011. 
FERREIRA, Y. C. de S. M. L.; SOBRINHO VASCONCELLOS, M.; VASCONCELLOS, A. M. de A. Co-gestão em Reserva Extrativista na Amazônia: inovação social para sustentabilidade? O caso da Resex Terra Grande do Pracuúba, Estado do Pará. P2P e Inovação, vol. 03, n. 01, pág. 91-109, 2017.

GOHN, M. da G. Conselhos gestores e participação sociopolítica. 4ª ed. São Paulo, Cortez, 2011.

GONÇALVES, M. T.; KAUCHAKJE, S.; MOREIRA, T. A. Modalidades de gestão social no Brasil. Situ-Revista Científica do Programa de Mestrado Profissional em Projeto, Produção e Gestão do Espaço Urbano, vol. 01, n.02, pág. 131-154, 2015.

LOSEKANN, C. Participação da sociedade civil na política ambiental do Governo Lula. Ambiente \& Sociedade, São Paulo, v. 15, n. 1, jan./abr. 2012.

MEDEIROS, R. P. Possibilidades e obstáculos a co-gestão adaptativa de sistemas pesqueiros artesanais: estudo de caso na área da Baía de Tijucas, litoral centro-norte do estado de Santa Catarina, no período de 2004 a 2008. Tese. Programa de Pós-Graduação em Sociologia Política da Universidade de Federal de Santa Catarina, 2009.

OLSON, M. The logic of collective action. Cambridge, MA: Harvard University Press, pág. 186, 1965.

OSTROM, E. Governing the commons: the evolution of institutions for collective action. Cambridge, New York: Cambridge University Press, pág. 280, 1990.

PERES, A. da C. Estudo Antropológico de uma comunidade na abrangência da Reserva Extrativista Marinha Caeté-Taperaçu (Bragança-Pará-Brasil). Belém 2011. Tese (Doutorado em Antropologia). Programa de Pós-Graduação em Ciências Sociais UFPA, Belém, pág. 300, 2011.

PIRES, E. L. S. et al. A Governança Territorial no Brasil: Conceitos e Modalidades. In: I Circuito de Debates Acadêmicos (CODE). Anais..., 2011.

RÊGO, R. S. Entre redes: Um estudo do sistema de representação e atuação do Conselho Deliberativo da RESEX Marinha de Cururupu. Maranhão, 2016. Monografia. (Bacharel em Ciências Sociais). Curso de Ciências Sociais da Universidade Federal do Maranhão - UFMA. Maranhão, pág. 75, 2016.

SILVA JUNIOR, S. R. da. Participação e relações de poder no Conselho Deliberativo da Reserva Extrativista Marinha de Caeté-Taperaçu, Bragança-PA. Belém, 2013.Tese (Doutorado em Ciências Sociais). Programa de Pós-Graduação em Ciências Sociais da Universidade Federal do Pará UFPA. Belém, pág. 129, 2013.

SILVA JUNIOR, S. R. da. et al. Conservação dos recursos naturais, práticas participativas e institucionalização: Reserva Extrativista de Caeté-Taperaçu/Amazônia Brasileira. Revista eletrônica de geografia e ciências sociais, vol. 18, n. 477, mai, 2014.

SILVA JUNIOR, S. R. da et al. Desafios da gestão participativa de recursos naturais em uma Reserva Extrativista Marinha no Pará. Novos Cadernos NAEA, vol. 21, n. 02, 2018.

TEISSERENC, M. J. da S. A. Politização, ambientalização e desenvolvimento territorial em reservas extrativistas. Caderno CRH, Salvador, vol. 29, n. 77, pág. 229-242, mai/ago, 2016.

TEISSERENC, P. Governança Territorial em Reservas Extrativistas. Revista: Pós Ci. Soc. vol.11, n. 22, pág. 19-46, jul/dez, 2014. 